\title{
Twenty years' experience of primary vaginal cancer treatment at one cancer centre: does residence status matter?
}

\author{
Olga P Matylevich ${ }^{1}$, Hanna V Trukhan², Olga I Zubets ${ }^{3}$ and Siarhei A. Mavrichev ${ }^{1}$ \\ ${ }^{1}$ Gynecologic Oncology Department, NN Alexandrov National Cancer Centre of Belarus, a/g Lesnoy-2, 223040 Minsk, Belarus \\ ${ }^{2}$ Department of Oncology, Belarusian Medical Academy of Postgraduate Education, Minsk, Belarus, Brovki Street, 3, build. 3, 220013 Minsk, Belarus \\ ${ }^{3}$ Cancer Control Department, NN Alexandrov National Cancer Centre of Belarus, a/g Lesnoy-2, 223040 Minsk, Belarus
}

\section{Abstract}

Objectives: To study the long-term results of the treatment of patients with vaginal cancer and to examine whether there are any differences in diagnostic and survival rates between urban and rural patients.

Methods: The data of 70 patients with primary vaginal cancer treated at NN Alexandrov National Cancer Centre of Belarus from 2000 to 2019 were included. The median age was 64 years (range $=56-75)$. Morphology in $91.4 \%(64 / 70)$ of the cases was squamous cell cancer, in $7.1 \%(5 / 70)$ it was adenocarcinoma and in $1.4 \%(1 / 70)$ it was adenosquamous carcinoma. In total, there were 31 patients from urban and 39 from rural areas. The groups were comparable in age (61 versus 67, $p=0.104)$, morphology $(p=0.188)$ and distribution of stages: stage I in 7 and 10 patients $(22.6 \%$ and $25.6 \%$, respectively; $p=$ 0.999 ), stage II in 14 and 16 patients ( $45.1 \%$ and $41.0 \%$, respectively; $p=0.810$ ), stage III in 6 and 6 patients (19.4\% and 15.4\%, respectively; $p=0.754)$ and stage IV in 4 and 7 patients (12.9\% and $18.0 \%$, respectively; $p=0.744)$.

Results The median follow-up time was 33 months (range $=1-220$ ). A total of 42 women died: 28 from progression of vaginal cancer and 14 from other diseases. Overall survival (OS) was $31.9 \pm 6.8 \%$, median survival was 41 months $(95 \% \mathrm{Cl}=0.0-105.3)$. Diseasespecific survival (DSS) for the entire group was $54.5 \pm 6.8 \%$; median was not reached. The overall survival rate of urban women was $44.8 \pm 10.6 \%$ and for rural it was $22.5 \pm 8.2 \%$ ( $p$ $=0.142)$; DSS was $57.6 \pm 10.5 \%$ and $53.0 \pm 8.4 \%(p=0.448)$, respectively.

Conclusion DSS rate was $54.0 \pm 6.8 \%$ and the OS rate did not exceed $31.9 \pm 6.8 \%$. Rural residence was not associated with late stage at diagnosis or receipt of treatment.

Keywords: vaginal cancer, long-term results, urban / rural patients, differences in diagnosis and survival

\section{Introduction}

Vaginal cancer is a rather rare pathology and accounts for only $1 \%-2 \%$ of all the cases of cancer of the female reproductive system; it most often occurs at the age of 60-70 years
Correspondence to: Olga P Matylevich Email: omatylevich@tut.by

ecancer 2021, 15:1267

https://doi.org/10.3332/ecancer.2021.1267

Published: $15 / 07 / 2021$

Received: 19/04/2021

Publication costs for this article were supported by ecancer (UK Charity number 1176307).

Copyright: $($ the authors; licensee ecancermedicalscience. This is an Open Access article distributed under the terms of the Creative Commons Attribution License (http:// creativecommons.org/licenses/by/4.0), which permits unrestricted use, distribution, and reproduction in any medium, provided the original work is properly cited. 
[1-3]. In the United States, 8,180 new cases of vaginal cancer are diagnosed annually and 1,530 patients die [4]. In the Republic of Belarus, about 35 new cases of vaginal cancer are detected annually and 12 patients die from this disease [5]. According to the literature, about $70 \%$ of all the cases of vaginal cancer are associated with HPV and are characterised by many of the same risk factors as cervical cancer: multiple sexual partners, early age at first intercourse and smoking [6-8]. The choice of treatment for patients with vaginal carcinoma depends on a number of factors, such as the stage of the disease, the anatomical location of the lesion, the histological structure of the tumour, the volume of the tumour and the age of the patient. In the case of vaginal cancer, a variety of treatments may be offered, including surgery, radiation therapy, chemotherapy or combinations thereof $[2-4,9]$.

There is evidence from some authors on the existence of differences in diagnosis and survival rates for cervical cancer, lung cancer, colorectal and other types of cancer between urban and rural residents due to health inequalities associated with cancer [10-13]. In Belarus, schemes for the diagnosis and treatment of vaginal cancer in urban and rural patients have not been studied.

The aim of this study was to summarise the experience of one cancer centre in treating vaginal cancer over a 20-year period and to evaluate the results of diagnosis and treatment of patients living in urban and rural areas.

\section{Methods}

\section{Patient selection}

The retrospective cohort study included data from 104 patients with vaginal malignant neoplasms (C52), whose treatment was carried out at NN Alexandrov National Cancer Centre of Belarus for the period from 2000 to 2019. Twenty-five women with multiple primary tumours and nine women with non-epithelial vaginal tumours (melanoma, sarcoma etc.) were excluded from the study.

Seventy patients with primary vaginal cancer met the inclusion criteria. All tumours were confirmed histologically. All International Federation of Gynaecology and Obstetrics (FIGO) 2009 [3] stages I-IV and the following histology were included: squamous cell carcinoma, adenocarcinoma and adenosquamous carcinoma. Patient demographics, pathological data and follow-up information were retrospectively collected from electronic medical records. This study was approved by the Ethics Committee of the NN Alexandrov National Cancer Centre (protocol No17), Minsk, Belarus, on 17 January 2020.

\section{Treatment}

Treatment was carried out in the vast majority of patients - in $81.4 \%(57 / 70)$ of the cases: with stage I of the disease in 94.1\% (16/17), with stage II in $83.3 \%(25 / 30)$ of the cases, with stage III in $91.7 \%$ (11/12) of the cases and with stage IV in $45.5 \%(5 / 11)$ of the cases. In 13 patients, treatment was not carried out due to the refusal of patients at stages I and II, as well as because of an incurable condition at stage IV.

At stage I of the disease, radiation therapy was most often used - a combination of external beam radiation therapy with intracavitary brachytherapy and/or interstitial brachytherapy - in 10 (62.5\%) patients and $6(37.5 \%)$ patients with upper vaginal disease underwent surgery, after which 2 patients received an adjuvant course of radiotherapy. At stage II, 16 (64.0\%) patients underwent a course of combined radiation therapy (external beam radiotherapy and brachytherapy), $4(16.0 \%)$ underwent a course of external radiation therapy with lack of conditions for brachytherapy, 5 (20.0\%) underwent surgery and 1 underwent a postoperative course of external beam radiation therapy. All (100\%) stage III patients underwent a course of combined chemoradiation therapy or external beam chemoradiation therapy. At stage IV of the disease, palliative radiation with chemotherapy was used.

\section{Statistical analysis}

Data were summarised using basic descriptive statistics. The main outcome of the study was survival time. The time period was calculated at the time of diagnosis. Survival rates were calculated according to Kaplan-Meier for the entire observation period. Comparison of survival in 
two groups was carried out according to the Log-rank test, and in groups of three or more using the $c^{2}$ criterion. Differences were considered statistically significant at $p<0.05$. All $p$-values were two-sided. The calculations were carried out using the Statistical Package for the Social Sciences (IBM SPSS Statistics for Windows version 23.0, Armonk, NY, USA).

\section{Results}

\section{Cohort characteristics}

We identified 70 patients with primary vaginal cancer. Patient and tumour characteristics are detailed in Table 1.

The median age was 64 years (range $=56-75)$. Morphology in 91.5\% (64/70) of the cases was squamous cell cancer, in 7.1\% (5/70) it was adenocarcinoma and in $1.4 \%(1 / 70)$ it was adenosquamous carcinoma. The distribution by the stages was as follows: stage I in 17 (24.3\%) patients, stage II in 30 (42.9\%) patients, stage III in 12 (17.1\%) patients and stage IV in 11 (15.7\%) patients.

In total, there were 31 patients from the city and 39 from the countryside. The groups were comparable for the following clinical and morphological characteristics: age $(p=0.104)$ - the age of urban women varied from 32 to 87 years, the median was 61 years, and the age of rural women varied from 51 to 73 years, the median was 67 years; morphological structure $(p=0.188)$; and stages of the disease: stage I in 7 and 10 patients (22.6\% and 25.6\%, respectively; $p=0.999)$, stage II in 14 and 16 patients $(45.2 \%$ and $41.0 \%$,respectively; $p=0.810)$, stage III in 6 and 6 patients (19.4\% and 15.4\%, respectively; $p=0.754)$ and stage IV in 4 and 7 patients $(12.9 \%$ and $17.9 \%$, respectively; $p=0.744)$ (Figure 1).

Table 1. Patient and tumour characteristics.

\begin{tabular}{|c|c|c|c|c|c|}
\hline Category & Total $(n=70)$ & Urban $(n=31)$ & Rural $(n=39)$ & \multicolumn{2}{|c|}{$p$-value } \\
\hline Age (years), median (range) & $64(56-75)$ & $61(32-87)$ & $67(51-73)$ & \multicolumn{2}{|c|}{0.104} \\
\hline \multicolumn{6}{|l|}{ Histology, $n$ (\%) } \\
\hline Squamous & $64(91.4 \%)$ & 27 (87.1\%) & 37 (94.9\%) & 0.395 & \multirow{3}{*}{0.188} \\
\hline Adenocarcinoma & $5(7.1 \%)$ & $3(9.7 \%)$ & $2(5.1 \%)$ & 0.649 & \\
\hline Adenosquamous & $1(1.4 \%)$ & $1(3.2 \%)$ & 0 & 0.443 & \\
\hline \multicolumn{6}{|l|}{ FIGO (2009) Stage, $n(\%)$} \\
\hline I & $17(24.3 \%)$ & $7(22.6 \%)$ & $10(25.6 \%)$ & 0.999 & \multirow{4}{*}{0.985} \\
\hline II & 30 (42.9\%) & $14(45.1 \%)$ & $16(41.0 \%)$ & 0.810 & \\
\hline III & 12 (17.1\%) & $6(19.4 \%)$ & $6(15.4 \%)$ & 0.754 & \\
\hline IV & $11(15.7 \%)$ & $4(12.9 \%)$ & $7(18.0 \%)$ & 0.744 & \\
\hline \multicolumn{6}{|l|}{ Treatment } \\
\hline Yes & $57(81.4 \%)$ & 27 (87.1\%) & $30(76.9 \%)$ & 0.440 & \multirow{2}{*}{0.280} \\
\hline No & $13(18.6 \%)$ & 4 (12.9\%) & 9 (23.1\%) & 0.440 & \\
\hline \multicolumn{6}{|l|}{ Relapses, $n$ (\%) } \\
\hline Yes & 7 & $2(6.5 \%)$ & $5(12.8 \%)$ & 0.452 & \multirow{2}{*}{0.381} \\
\hline No & 63 & 29 (93.5\%) & 34 (87.2\%) & 0.452 & \\
\hline $\begin{array}{l}\text { Follow-up (months), median } \\
\text { (range) }\end{array}$ & $33(1-219.6)$ & $43(1-219.6)$ & $21.4(1-191.6)$ & \multicolumn{2}{|c|}{0.449} \\
\hline
\end{tabular}

Abbreviations: FIGO, International Federation of Gynaecology and Obstetrics 


\section{Survival outcomes}

The median follow-up time was 33 months (range $=1-220$ ). A total of 42 women died: 28 from the progression of vaginal cancer and 14 from other diseases. The overall survival (OS) rate was $31.9 \pm 6.8 \%$ and median survival was 41 months $(95 \% \mathrm{Cl}=0.0-105.3)$. The diseasespecific survival (DSS) rate for the entire group was $54.5 \pm 6.8 \%$; median was not reached. The DSS by stages was as follows: at I stage it was $100 \%$, at stage II it was $57.3 \pm 10.9 \%$, at stage III it was $33.3 \pm 13.6 \%$, no patients with stage IV survived a year and 1-year survival was 11.4 $\pm 10.5 \%$ (Figure 2).

With a median follow-up of 13 months (range $=1-23$ ), seven (10\%) patients had recurrence and all patients died. In the remaining, the cumulative eventless survival rate after the diagnosis was $85.3 \pm 5.3 \%$.

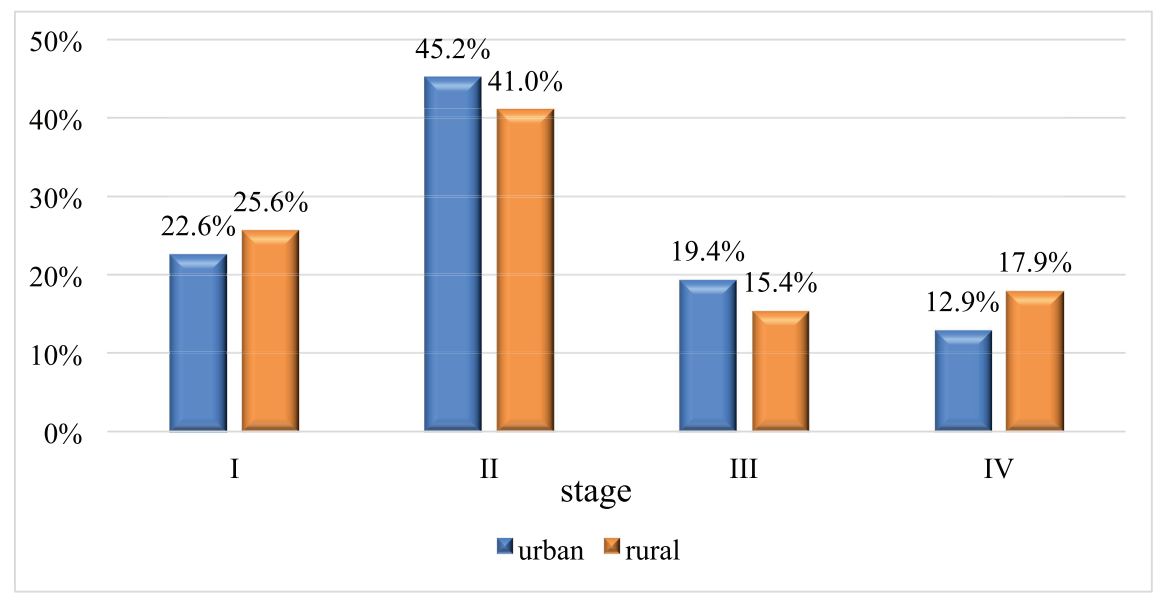

Figure 1. Vaginal cancer case distribution in urban and rural areas by stages of the disease.

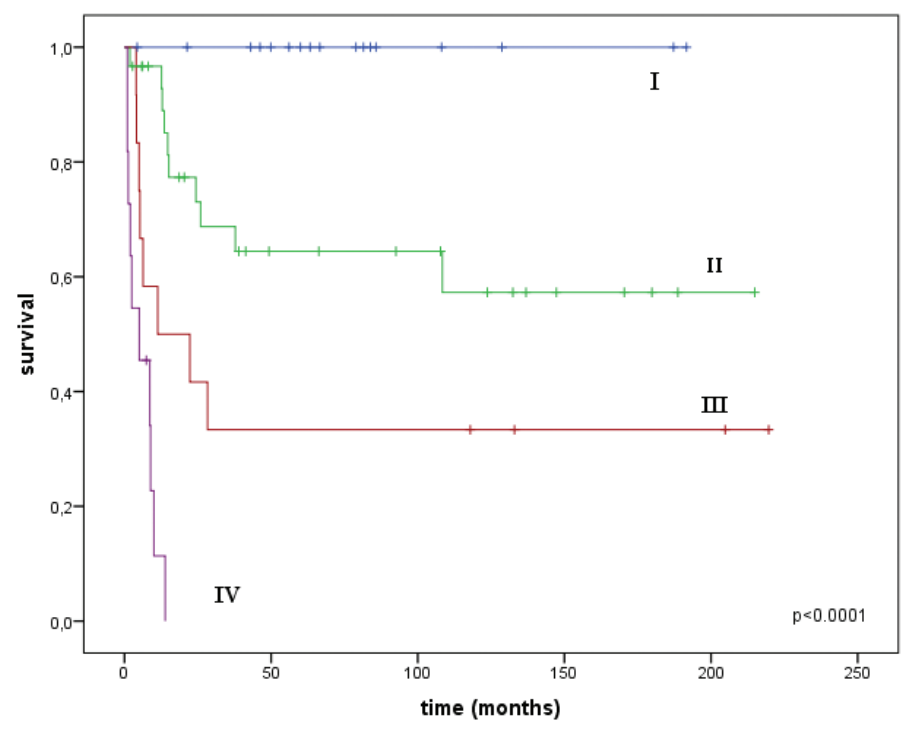

Figure 2. DSS curves for the entire group by stages. 
The median follow-up time was 43 months for urban patients (range $=1-220)$ and 21.4 months for rural patients (range $=1-192 ; p=0.449$ ). We compared the survival outcomes between urban and rural groups. The overall survival rate of urban women was $44.8 \pm 10.6 \%$ and for rural women it was $22.5 \pm 8.2 \%(p=0.142)$, without statistically significant differences (Figure 3).

The disease-specific survival was also similar between the two groups: for women in the city it was $57.6 \pm 10.5 \%$ and for rural women it was $53.0 \pm 8.4 \%(p=0.448)$ (Figure 4).

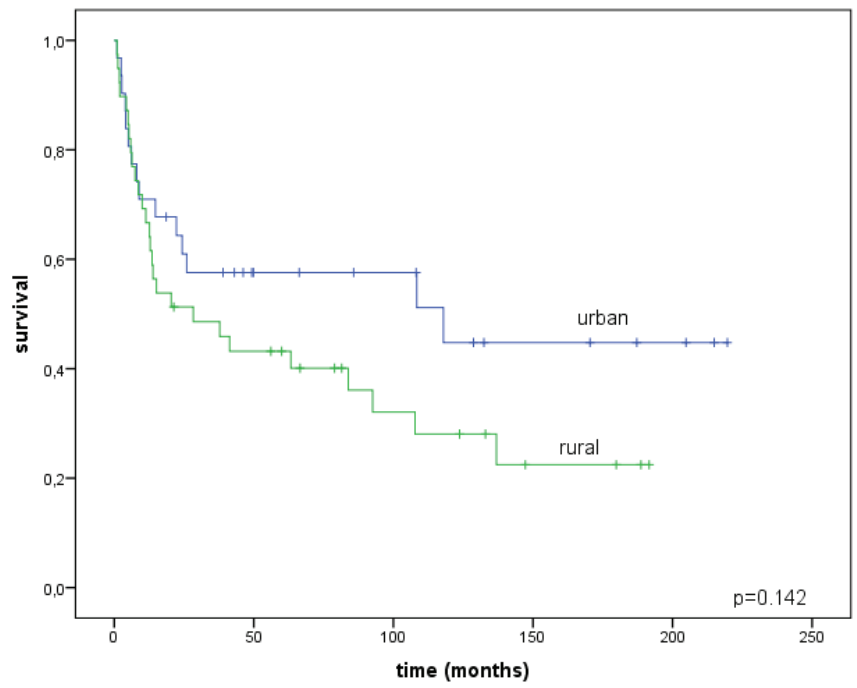

Figure 3. Overall survival rates for urban and rural patients.

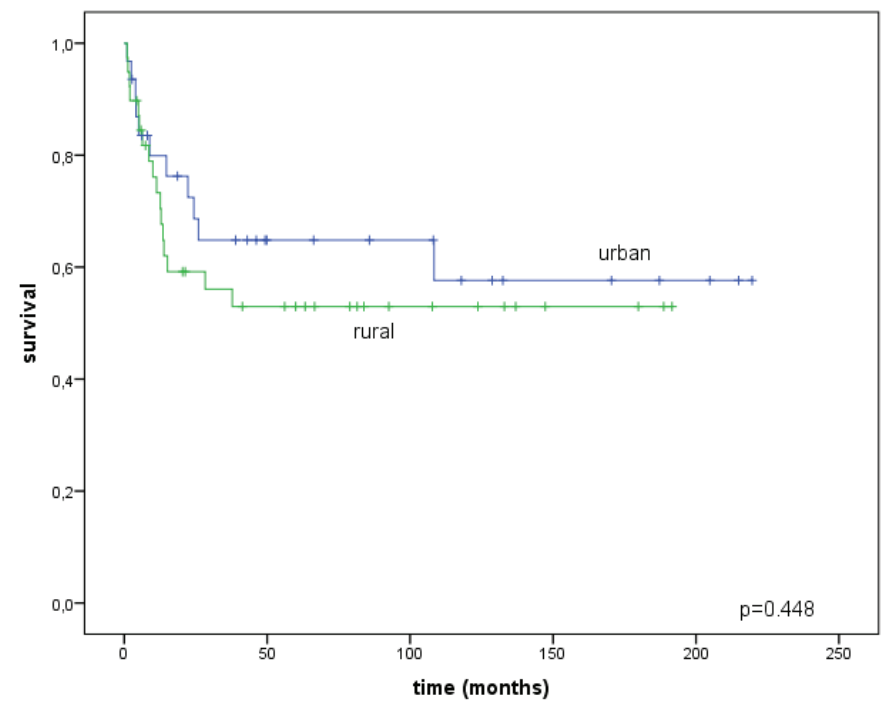

Figure 4. Disease-specific survival curves for urban/rural residents. 
The DSS rate of urban and rural residents by stages was comparable: for stage I it was $100 \%$ in both groups; for stage II it was $53.0 \pm 18.7 \%$ and $59.5 \pm 12.9 \%$, respectively ( $p=0.670$ ); and for stage III it was $50.0 \pm 20.4 \%$ and $16.7 \pm 15.2 \%$, respectively $(p=0.415)$. Patients with stage IV in the group of urban women died within 5 months and rural women within 1 year (Figure 5).

\section{Discussion}

Primary vaginal cancer is rare. Historically, these cancers are more common in older women and postmenopausal women [3]. The median age of our patient population was 64 years, which confirms the literature data.

Since most vaginal malignancies have squamous cell histology, the aetiology is common with cervical cancer. This is the persistence of highrisk oncogenic HPV infections. According to our data, the predominant tumour structure was also squamous cell carcinoma (91.5\%), other morphological variants were extremely rare.

Because vaginal cancer is uncommon, in the published literature there is much debate and controversy over the preferred treatment. Most of the management is extrapolated from cervical cancer due to similar aetiology and anatomical location. With early diagnosis, both surgical resection and radiation therapy can be curative options. In most patients, especially in advanced stages, radiation, consisting of external beam radiation and brachytherapy, plays a central role. Accordingly, the outcomes are influenced by the experience of the medical team in treating this unique tumour [14-16]. In our study, majority of the patients received anti-tumour treatment (82.9\%). The most frequent method of treatment at stages I-III was a definitive radiation therapy: in $62.5 \%, 80 \%$ and $100 \%$ of the cases, respectively. The DSS rate was $54.0 \pm 6.7 \%$ and the overall survival rate did not exceed $31.6 \pm 6.7 \%$. The DSS by stages was as follows: at stage I stage it was $100 \%$, at stage II it was $57.3 \pm 10.9 \%$, at stage III it was $33.3 \pm 13.6 \%$, none of the patients with stage IV survived for a year and 1 -year survival rate was $11.4 \pm 10.5 \%$. Relatively, 5-year survival in a larger series ranged from 64 to $84 \%$ for stage I, 53-58\% for stage II, 36\% for stage III and $18 \%-36 \%$ for stage IV [17]. Our data are consistent with the current literature rates, with the exception of stage IV of the disease [14-18]. The low survival rate of patients with advanced stage of vaginal cancer is attributed to the lack of effective treatment for this category of patients in our setting. Thus, given the limited options for patients with recurrent and metastatic cervical cancer, which is similar in nature to vaginal cancer, Kahn et al [19] recommend considering the possibility of immunotherapy with pembrolizumab in PD-L1-positive patients.

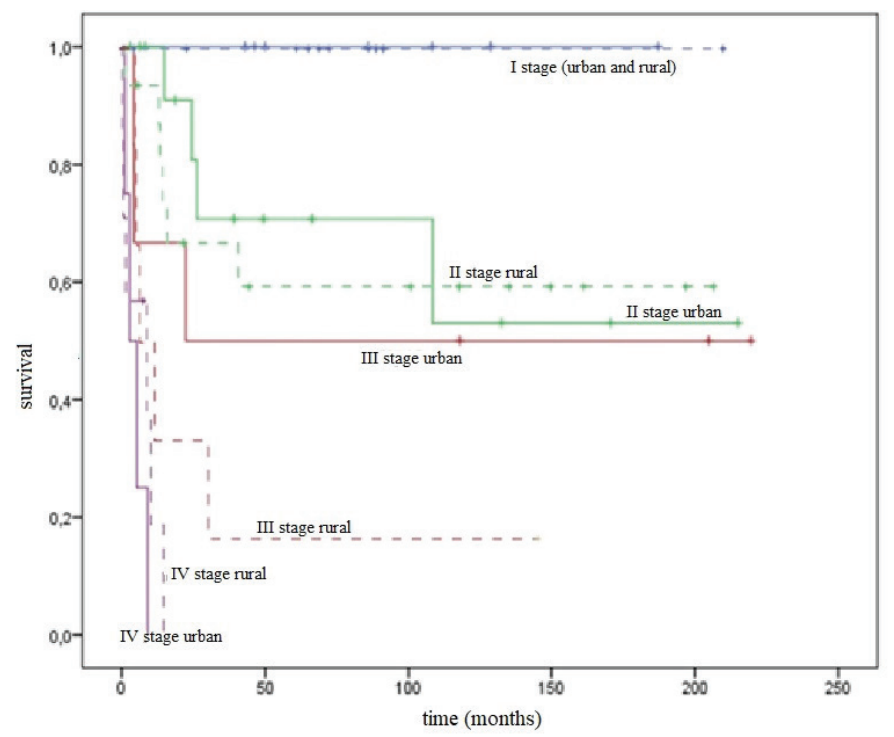

Figure 5. DSS curves for urban/rural residents by stages. 
Few studies have examined the role of residence in diagnosis and treatment outcomes in patients with cervical cancer, which is the closest in aetiology to vaginal cancer and other cancers [10-13]. Singh [10] reports that in the United States the 5-year survival rate for black women diagnosed with cervical cancer was $50.8 \%$ in the non-metropolitan areas, compared with $60.2 \%$ for black women and $71.0 \%$ for white women in metropolitan areas. Differences in survival were observed after taking into account the stage of the disease. Urban-rural disparities in cervical cancer incidence persist, despite sharp declines in morbidity and mortality. In our study, if we analyse the role of the place of residence, there are no differences in stage distribution between urban and rural groups. If we look at the survival outcomes, there are no discrepancies in overall, disease-specific survival and survival by the stages between women living in urban and rural areas. In our opinion, this is due to the presence of centralised oncological care in Belarus and the provision of the healthcare system with universal access to medical care, which is free at the point of use [20].

This study is limited by its retrospective cohort analysis with a small sample size and being a single cancer centre study with possible referral bias. However, survival of patients in present report was compared to the literature data. Both OS and DSS are consistent with current literature estimates [14-18].

\section{Conclusion}

Because primary vaginal cancer is rare, treatment is complex and often individualised. Therefore, it is recommended, whenever possible, to refer women diagnosed with primary vaginal cancer to specialised cancer centres. In our study, there were no differences in the stages of diagnosis and treatment outcomes between urban and rural patients, which indicate the same access to diagnostic and medical services.

\section{Conflicts of interest}

The authors declare that they have no conflicts of interest.

\section{Authors' contribution}

OPM carried out data collection, analysis and wrote the manuscript. HVT and SAM were involved in the treatment of patients, analysis and manuscript editing. OIZ carried out the statistical analysis. All authors approved the final version of the manuscript.

\section{Acknowledgments and funding}

The authors are grateful to ecancer for covering the cost of publication (UK Charity number 1176307).

\section{References}

1. Siegel RL, Miller KD, and Jemal A (2016) Cancer statistics, 2016 CA Cancer J Clin 66(1) 7-30 https://doi.org/10.3322/caac.21332 PMID: 26742998

2. Eifel P, Klopp AH, and Berek JS, et al (2019) Chapter 74: cancer of the cervix, vagina, and vulva DeVita, Hellman, and Rosenberg's Cancer: Principles and Practice of Oncology 11th edn eds VT DeVita, TS Lawrence, SA Rosenberg (Philadelphia: Lippincott Williams \& Wilkins) pp $1171-1210$

3. Adams TS and Cuello MA (2018) Cancer of the vagina Int J Gynaecol Obstet 143(Suppl 2) 14-21 https://doi.org/10.1002/ijgo.12610 PMID: 30306589 
4. American Cancer Society (2021) Cancer Facts \& Figures 2021 (Atlanta: American Cancer Society)

5. Okeanov AE et al (2018) Statistics of Oncological Diseases in the Republic of Belarus (2008-2017) ed OG Sukonko (Minsk: N.N. Aleksandrov RNPC OMR) p 286 [In Russ]

6. Sinno AK, Saraiya M, and Thompson TD, et al (2014) Human papillomavirus genotype prevalence in invasive vaginal cancer from a registry-based population Obstet Gynecol 123(4) 817-821 https://doi.org/10.1097/AOG.0000000000000171 PMID: 24785610 PMCID: 4009490

7. Larsson GL, Helenius G, and Andersson S, et al (2013) Prognostic impact of human papilloma virus (HPV) genotyping and HPV-16 subtyping in vaginal carcinoma Gynecol Oncol 129(2) 406-411 https://doi.org/10.1016/j.ygyno.2013.02.004 PMID: 23402906

8. Daling JR, Madeleine MM, and Schwartz SM, et al (2002) A population-based study of squamous cell vaginal cancer: HPV and cofactors Gynecol Oncol 84(2) 263-270 https://doi.org/10.1006/gyno.2001.6502 PMID: 11812085

9. https://www2.tri-kobe.org/nccn/guideline/gynecological/english/vulvar.pdf

10. Singh GK (2012) Rural-urban trends and patterns in cervical cancer mortality, incidence, stage, and survival in the United States, 1950-2008 J Community Health 37(1) 217-223 https://doi.org/10.1007/s10900-011-9439-6

11. Johnson AM, Hines RB, and Johnson JA 3rd, et al (2014) Treatment and survival disparities in lung cancer: the effect of social environment and place of residence Lung Cancer 83(3) 401-407 https://doi.org/10.1016/j.lungcan.2014.01.008 PMID: 24491311

12. Hines R, Markossian T, and Johnson A, et al (2014) Geographic residency status and census tract socioeconomic status as determinants of colorectal cancer outcomes Am J Public Health 104(3) e63-e71 https://doi.org/10.2105/AJPH.2013.301572 PMID: 24432920 PMCID: 3953793

13. Markossian TW and Hines RB (2012) Disparities in late stage diagnosis, treatment, and breast cancer-related death by race, age, and rural residence among women in Georgia Women Health 52(4) 317-335 https://doi.org/10.1080/03630242.2012.674091 PMID: 22591230

14. Gardner CS, Sunil J, and Klopp AH, et al (2015) Primary vaginal cancer: role of MRI in diagnosis, staging and treatment Br J Radiol 88(1052) 20150033 https://doi.org/10.1259/bjr.20150033 PMID: 25966291 PMCID: 4651370

15. Frank SJ, Jhingran A, and Levenback C, et al (2005) Definitive radiation therapy for squamous cell carcinoma of the vagina Int J Radiat Oncol Biol Phys 62(1) 138-147 https://doi.org/10.1016/j.ijrobp.2004.09.032 PMID: 15850914

16. Creasman WT (2005) Vaginal cancers Curr Opin Obstet Gynecol 17(1) 71-76 https://doi.org/10.1097/00001703-200502000-00013 PMID: 15711415

17. de Crevoisier R, Sanfilippo N, and Gerbaulet A, et al (2007) Exclusive radiotherapy for primary squamous cell carcinoma of the vagina Radiother Oncol 85 362-370 https://doi.org/10.1016/j.radonc.2007.09.015 PMID: 17963909

18. Pingley S, Shrivastava SK, and Sarin R, et al (2000) Primary carcinoma of the vagina: tata memorial hospital experience Int J Radiat Oncol Biol Phys 46(1) 101-108 https://doi.org/10.1016/S0360-3016(99)00360-0 PMID: 10656380

19. Kahn RM, Gordhandas S, and Craig K, et al (2020) Cervical carcinoma in the setting of uterovaginal prolapse: comparing standard versus tailored management Ecancermedicalscience 141043 https://doi.org/10.3332/ecancer.2020.1043 PMID: 32565896 PMCID: 7289612

20. Richardson E, Malakhova I, and Novik I, et al (2013) Belarus: health system review Health Syst Transit 15(5) 1-118 PMID: 24334702 